
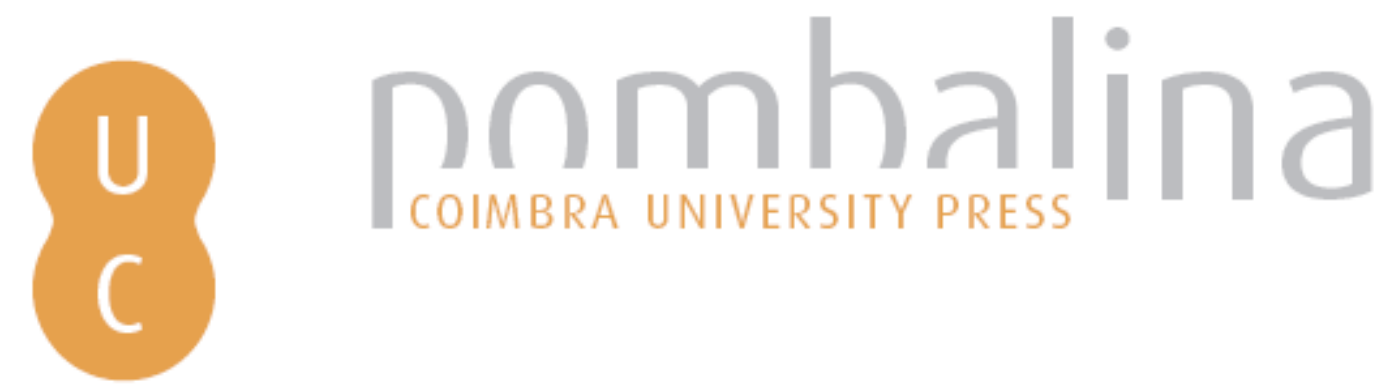

\title{
Los delitos contra la propiedad cometidos por las mozas de servicio en Castilla a finales del Antiguo Régimen
}

\author{
Autor(es): $\quad$ Lozano Ruiz, Carlos \\ Publicado por: Imprensa da Universidade de Coimbra \\ URL \\ persistente: URI:http://hdl.handle.net/10316.2/37195 \\ DOI: \\ DOI:978-989-26-1033-7 (PDF); DOI:http://dx.doi.org/10.14195/978-989- \\ 26-1033-7_8
}

Accessed : $\quad$ 26-Apr-2023 14:09:33

A navegação consulta e descarregamento dos títulos inseridos nas Bibliotecas Digitais UC Digitalis, UC Pombalina e UC Impactum, pressupõem a aceitação plena e sem reservas dos Termos e Condições de Uso destas Bibliotecas Digitais, disponíveis em https://digitalis.uc.pt/pt-pt/termos.

Conforme exposto nos referidos Termos e Condições de Uso, o descarregamento de títulos de acesso restrito requer uma licença válida de autorização devendo o utilizador aceder ao(s) documento(s) a partir de um endereço de IP da instituição detentora da supramencionada licença.

Ao utilizador é apenas permitido o descarregamento para uso pessoal, pelo que o emprego do(s) título(s) descarregado(s) para outro fim, designadamente comercial, carece de autorização do respetivo autor ou editor da obra.

Na medida em que todas as obras da UC Digitalis se encontram protegidas pelo Código do Direito de Autor e Direitos Conexos e demais legislação aplicável, toda a cópia, parcial ou total, deste documento, nos casos em que é legalmente admitida, deverá conter ou fazer-se acompanhar por este aviso.

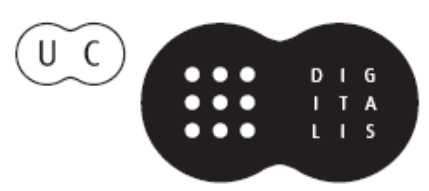


AS MULHERES PERANTE

OS TRIBUNAIS DO

ANTIGO REGIIME NA PENÍNSULA JBÉRICA

ISABEL M.R. MENDES DRUMOND BRAGA MARGARITA TORREMOCHA HERNÁNDEZ (COORDENAÇÃO)

IMPRENSA DA

UNIVERSIDADE

DE COIMBRA

COIMBRA

UNIVERSITY

PRESS 


\section{LOS DELITOS CONTRA LA PROPIEDADCOMETIDOS POR LAS MOZAS DE SERVICIO EN CASTILLA A FINALES DELANTIGUO RÉGIMEN}

Carlos Lozano Ruiz Universidad de Valladolid 1

\section{1-Introducción. El servicio doméstico. Entre la buena criada y la criada ladrona}

El servicio doméstico siguió siendo para las mujeres, a finales del Antiguo Régimen, "la vía más práctica y rápida para entrar en la economía urbana aunque en la segunda mitad del XVIII la industria les diese algunas oportunidades más" 2 . Tal es así, que esta fue "la vía laboral mayoritariamente adoptada por la población femenina, el primer medio, sino el único, que se ofrecía a muchas mujeres para lograr reunir la ansiada dote" 3 , por lo que el servicio que prestaban no era un fin en sí mismo sino que este tuvo una orientación y una finalidad muy clara en la mayoría de los casos. Esta ocupación viene, por lo tanto, a cuestionar

\footnotetext{
${ }^{1}$ Beneficiario del Programa de Formación del Profesorado Universitario (FPU) del Ministerio de Educación, Cultura y Deporte (España). Referencia 2010/0154. Miembro del Proyecto HAR2012- 31909, financiado por el Ministerio de Economía y Competitividad. Proyectos de Investigación Fundamental. VI Programa Nacional de Investigación Científica (España), Desarrollo e Innovación Tecnológica, 2008-2011.

2 Ofelia Rey Castelao, "Mujeres, trabajo y migraciones urbanas en España durante la segunda mitad del siglo XVIII", Revista de Historiografía, 16, Madrid, 2012, p. 51.

3 Serrana Rial García, Las mujeres en la economía urbana del Antiguo Régimen: Santiago durante el siglo XVIII, A Coruña, Ediciós do Castro, 1995, p. 202.
} 
la conocida afirmación, que desde algunos sectores de la historiografía se ha venido repitiendo, relativa a que "las mujeres contribuyeron por primera vez y de forma decisiva a la economía familiar durante la primera revolución industrial" ${ }^{4}$. En esta línea, el trabajo desempeñado por las mujeres desde el servicio doméstico se ha considerado como un "ejemplo de la "terciarización" de la estructura ocupacional femenina en la época preindustrial" 5 .

Tal y como señaló Aragón Mateos "historiar el mundo de la servidumbre es desde luego analizar una relación, un intercambio" ${ }^{6}$. En ocasiones, el grado de afectividad que se generaba entre los amos y las amas respecto a sus domésticos se acababa traduciendo en generosas mandas testamentarias, y es que las criadas, más allá de su trabajo, "también aconsejan, también ayudan y son los pies y manos de sus señores" 7 .

\footnotetext{
${ }^{4}$ Montserrat Carbonell i Esteller, "Las mujeres pobres en el Setecientos", Historia Social, $n^{\circ} 8$, Valencia, 1990 , p. 126. Como refleja dicha autora, las mujeres, en unos momentos anteriores a la primera Revolución Industrial ya habrían aportado su trabajo, no solo en lo relativo al consumo y a la reproducción, sino también en la producción y distribución de productos primarios, mercancías y servicios, siendo su actividad decisiva para la economía familiar. Algo que se evidencia desde el mismo momento en que "la inmensa mayoría de las mujeres tenía que trabajar para sobrevivir", Montserrat Carbonell i Esteller, "Trabajo femenino y economías familiares", Historia de las mujeres en España y América Latina, coordinadora Isabel Morant, Madrid, Cátedra, 2005, p. 244. No obstante, como ha señalado López Cordón, no se deben olvidar los problemas existentes a la hora de llevar a cabo una cuantificación de dicha realidad, pues "conocer qué significa, en términos económicos, el trabajo de la mujer en una sociedad del Antiguo Régimen es, no solo difícil, sino probablemente imposible”, María Victoria López-Cordón Cortezo, "La situación de la mujer a fines del Antiguo Régimen", Mujer y sociedad en España: 17001975, coordinadora Rosa María Capel Martínez, Madrid, Ministerio de Cultura, Dirección General de Juventud y Promoción Socio-cultural, 1986, p. 64. Igualmente, respecto al tema que aquí nos interesa más, el del servicio doméstico, conviene señalar que también encontramos una dificultad análoga pues "con los parámetros de que se dispone no es posible cuantificar realmente qué porcentaje de mujeres se dedicaba al servicio doméstico", Josefina Méndez Vázquez, "Escuelas para criadas: un plan de formación profesional en el Madrid de la España Ilustrada", Impulsando la Historia desde la historia de las mujeres, editoras Pilar Díez Sánchez, Gloria Franco Rubio, María Jesús Fuente Pérez, Huelva, Universidad de Huelva, 2012, p. 332.

5 Serrana Rial García, "El servicio doméstico: vía laboral para las mujeres en Santiago de Compostela a finales del Antiguo Régimen", El trabajo de la mujer. Pasado y presente, Málaga, Diputación Provincial, 1996, p. 313.

${ }^{6}$ Santiago Aragón Mateos, "Amos y criados en la Extremadura dieciochesca", Actas del Congreso Internacional sobre "Carlos III y la Ilustración" (Economía y sociedad), Madrid, Ministerio de Cultura, 1989, p. 404.

7 Miguel Herrero, Oficios populares en la sociedad de Lope de Vega, Madrid, Castalia, 1977 , p. 44.
} 
Sin embargo, esa actitud respecto a las mandas sabemos que no se encontraba muy generalizada ${ }^{8}$.

Mucho más extendida se encontraba en el imaginario colectivo la idea de la moza de servicio como un elemento peligroso al que sus amos debían vigilar e instruir continuamente, idea que se transmitió, entre otras vías, por la literatura, desde comienzos de la Modernidad. Por ejemplo, fray Luis de León, en La perfecta casada, va a reflejar estas ideas incidiendo, especialmente, en la importancia de la vigilancia del ama a las criadas en momentos como el descanso en el hogar, para evitar, sobre todo, que estas robasen ${ }^{9}$, así como en la instrucción diaria ${ }^{10}$. Pero no solamente en la literatura religiosa y moralizante vamos a encontrar esa imagen de la doméstica sino también en la novela picaresca ${ }^{11}$. Lo que más nos interesa comprobar en estos testimonios literarios de comienzos

8 Vid. María Concepción Valenzuela Robles, "Las relaciones afectivas entre amos y servidumbre femenina a través de las mandas testamentarias. Málaga (1496-1520)", Vidas y recursos de mujeres durante el Antiguo Régimen, Málaga, Servicio de Publicaciones de la Universidad de Málaga, 1997, p. 45.

9 "De manera que ha de madrugar la casada para que madrugue su familia. Porque ha de entender que su casa es su cuerpo, y que ella es el alma dél, y que, como los miembros no se mueven si no son movidos del alma, así sus criadas, si no las menea ella y las levanta y mueve a sus obras, no se sabrán menear. Y cuando las criadas madrugasen por sí durmiendo su ama y no la teniendo por testigo y por guarda suya, es peor que madruguen, porque entonces la casa, por aquel espacio de tiempo, es como pueblo sin rey y sin ley, y como comunidad sin cabeza; y no se levantan a servir, sino a robar y destruir, y es el propio tiempo para cuando ellos guardan sus hechos", fray Luis de León, La perfecta casada, edición de Mercedes Etreros, Madrid, Taurus, 1987, pp. 110-111.

10 "Y demás desto, del cuidado del ama aprenden las criadas a ser cuidadosas, y no osan tener en poco aquello en que ven que se emplea la diligencia y el mandamiento de su señora; y como conocen que su vista y provisión della se extiende por todo, paréceles, y con razón, que en todo cuanto hacen la tienen como por testigo y presente, y así se animan no solo a tratar con fidelidad sus obras y oficios, sino también a aventajarse señaladamente en ellos". Ibídem, p. 114.

11 Entre las numerosas citas que se podrían insertar a este respecto, hemos optado por la siguiente, donde se nos da una visión particular tanto del criado como de la criada: "Acordábaseme lo que en las cosas domésticas costaba un criado bellaco, sisador, mentiroso, como los de hogaño. Y si va por el atajo, ha de ser tonto, puerco, descuidado, flojo, perezoso, costal de malicias, embudo de chismes, lenguaz en responder, mudo en lo que importa hablar, necio y desvergonzado en gruñir. Una moza o ama que quiere servir de todo, sucia, ladrona, con un hermano, pariente o primo, para quien destaja tantas noches cada semana; amiga de servir a un hombre solo, de traer la mantilla en el hombro, que le den ración y ella se tiene cuidado de la quitación, cuando halla la ocasión; y ha de beber un poquito de vino, porque es enferma del estómago”, Mateo Alemán, Guzmán de Alfarache, edición de Benito Brancaforte, Madrid, Akal, 1996, pp. 182-183. 
de la Modernidad es cómo ya desde el siglo XVI, encontramos, entre otros aspectos, esa asociación de la moza de servicio como ladrona. Una asociación que se va a perpetuar y va a formar parte de la mentalidad castellana durante el Antiguo Régimen. Tal es así que "este era un estereotipo profundamente enraizado en las representaciones de los amos sobre los sirvientes en todas las sociedades europeas que hacían hincapié en la imagen del "criado-ladrón"12. En todo caso, conviene señalar que este no era sino un aspecto negativo más que se sumaba a la pésima imagen que ya desde la Edad Media ${ }^{13}$, y durante toda la Edad Moderna, se tuvo de las criadas ${ }^{14}$.

\section{2-Los hurtos en la Edad Moderna. Algunas observaciones}

No hay duda de que los hurtos y robos domésticos fueron, en general, más castigados en el ámbito privado que en el ámbito judicial. Eso no fue obstáculo, no obstante, para que toda una serie de pleitos pasasen por las distintas justicias existentes durante el Antiguo Régimen. Esto ha permitido la elaboración de algunos estudios que han centrado su interés en los momentos finales de la Edad Media y los comienzos de la Edad Moderna, en los que se ha cuantificado, mediante porcentajes,

\footnotetext{
12 Juan García Cárcamo, "Criados contra amos: la condición social de los sirvientes y los conflictos económicos con sus patronos en Vizcaya (siglos XVIII y XIX)”, Cuadernos de Sección. Historia-Geografía, 23, 1995, p. 126.

13 Fueron ya vistas como alborotadoras, causantes de destrozos, por entrar, por ejemplo, a tierras ajenas, y sus conductas personales fueron un motivo de preocupación para los concejos. Vid. María Isabel del Val, "Mujer y trabajo en Castilla al final de la Edad Media", Aragón en la Edad Media, no 14-15, 2, Zaragoza, 1999, pp. 1593-1595.

14 "Se decía de ellas que eran holgazanas, propensas al robo, ponían condiciones laborales a sus amas y amos, no tenían recato al tratar con los varones y resultaba muy difícil poder controlarlas porque cambiaban constantemente de casa", Emilia Martínez Ruiz y José Garrido Arredondo, "El servicio doméstico femenino en la Edad Moderna", Estudios en bomenaje al profesor José Szmolka Clares, coordinadores Antonio Luis Cortés Peña, Miguel Luis López-Guadalupe Muñoz, Francisco Sánchez-Montes González, Granada, Universidad de Granada, 2005, p. 422. Algunos de esos comportamientos que se las achacaban las llevaron hasta los propios tribunales, como se analiza en Francisco Javier Lorenzo Pinar, "Los criados salmantinos durante el siglo XVII (1601-1650): conflictividad social y actitudes ante la muerte (II)", Studia Histórica, Historia Moderna, 31, Salamanca, 2009, pp. 276-291.
} 
la participación femenina en determinados delitos ${ }^{15}$, y que, junto con otros, han venido a cuestionar la denominada teoría de la transición de la violencia al robo ${ }^{16}$. Pero este fenómeno no se ha analizado durante los inicios de la Modernidad, sino también durante los momentos finales de la misma. A este respecto, y a pesar de las limitaciones que plantea, se debe señalar, sin duda, el estudio de Palop Ramos, quien considera que los hurtos y robos fueron la transgresión más numerosa, no solo de su grupo, sino de todo el elenco delictivo tratado, así como en el que más personas confluyen ${ }^{17}$. Tampoco han faltado estudios sobre la

15 Vid. Juan Miguel Mendoza Garrido, "Sobre la delincuencia femenina en Castilla a fines de la Edad Media”, Mujer, marginación y violencia entre la Edad Media y los tiempos modernos, coordinador Ricardo Córdoba de la Llave, Córdoba, Servicio de Publicaciones, Universidad de Córdoba, 2006, pp. 75-126. En dicho estudio se analiza la documentación relativa a los alcaldes de Casa y Corte y a los pleitos que llegaron a la Real Chancillería de Ciudad Real-Granada (1495-1507) así como los delitos registrados en la Santa Hermandad Vieja de Ciudad Real para el período 1491-1525. Para que podamos hacernos una idea sobre la participación de la mujer en los denominados delitos contra la propiedad en aquel momento y en aquellos tribunales, hemos considerado oportuno reflejar las cifras de participación femenina en cada uno de ellos. Mientras que los porcentajes de dicha participación en los delitos contra la propiedad en el caso de las actuaciones de los alcaldes de Casa y Corte y en los pleitos de la Real Chancillería de Ciudad Real-Granada, son similares, un $15,78 \%$ en el primer caso y un 15, $38 \%$ en el segundo, una situación distinta sucede en el último de los tribunales, el de la Santa Hermandad Vieja de Ciudad Real, en el que dicho porcentaje se eleva hasta el $25 \%$.

16 El estudio anteriormente señalado, así como también otros existentes, vienen a reflejar que las cifras que se van obteniendo ponen en duda "el patrón de delincuencia medieval comúnmente aceptado y que suele definirse por el peso claramente destacado de los delitos contra las personas y especialmente focalizado en los fenómenos de violencia interpersonal", detectándose, en definitiva, que el peso de esos delitos contra la propiedad ya fueron realmente importantes en el tránsito de la Edad Media a la Moderna. Vid. Juan Miguel Mendoza Garrido, Clara Almagro Vidal, María Ángeles Martín Romera, Luis Rafael Villegas Díez, "Delincuencia y justicia en la Chancillería de Ciudad Real y Granada (14951510). Primera parte. Estudio", Clío \& Crimen: Revista del Centro de Historia del Crimen de Durango, $\mathrm{n}^{\circ} 4$, Durango, 2007, pp. 353-488.

17 José Miguel Palop Ramos, "Delitos y penas en la España del siglo XVIII", Estudis: Revista de Historia Moderna, $\mathrm{n}^{\circ}$ 22, Valencia, 1996, p. 83. Para el tribunal de la Real Chancillería de Valladolid, según las cifras aportadas por este investigador, el grupo delictivo contra la propiedad supuso un 39,6\%, mientras que respecto al total de los acusados por dichos delitos este porcentaje representó el $49 \%$. Es importante reseñar el abrumador peso de los delitos de hurto y robo dentro de este grupo (78), frente a los de destrucción de bienes (1) y estafa (3). Será en los primeros en los que centraremos nuestro estudio, pues, al fin y al cabo, fueron estos los que protagonizaron de un modo totalmente destacado las mozas de servicio. Algo distinta fue la realidad de los delitos contra la propiedad en la otra Chancillería, la de Granada, en la que ya no es el grupo delictivo con mayor peso (delitos contra la persona) si bien sigue siendo el que posee un mayor número de acusados $(33,9 \%)$. Aunque nos vayamos a centrar en los hurtos y robos, no debemos olvidar que las mujeres también protagonizaron durante esos momentos toda una serie de pleitos por motivos diversos, 
delincuencia, en este caso femenina, en otros ámbitos lejanos al castellano centrados en ese siglo ${ }^{18}$.

\section{3-Las criadas y los hurtos a través de los pleitos de la Real Chancillería de Valladolid}

De lo que no cabe duda es de que "junto a la violencia criminal, la delincuencia contra la propiedad constituyó la actividad ilegal que más alcance tuvo en las sociedades de la Europa preindustrial"19. Y ante este fenómeno nuestras protagonistas, las mozas de servicio, no quedaron al margen. Unas mujeres que, aunque no constituían un grupo marginal sensu estricto, sí que formaron "un conjunto de mal encaje en el tejido social" 20 . Distintos factores, entre ellos, especialmente, su situación de desamparo, su desarraigo familiar y la falta de tutela por parte del padre o marido, tan importante en aquella sociedad, o la necesidad, muchas veces, de completar sus ingresos de cara a la dote, llevaron a que ese servicio se prolongase en el tiempo ${ }^{21}$, pero también a que, en no pocas

siendo fiel reflejo de ello, por ejemplo, el estudio de Margarita Ortega López, "Protestas de las mujeres castellanas contra el orden patriarcal privado durante el siglo XVIII", Cuadernos de Historia Moderna, $\mathrm{n}^{\circ} 19$, Madrid, 1997, pp. 65-90, en el que podemos apreciar cómo, ante aquellas circunstancias, en que el varón se extralimitaba o no cumplía su función protectora, las mujeres no dejaron de acudir a los tribunales para resolver sus conflictos.

18 Vid. José Sánchez-Arcilla Bernal, "La delincuencia femenina en México a finales del siglo XVIII", Cuadernos de historia del Derecho, no 20, Madrid, 2013, pp. 89-154. El análisis, que se centra en el ámbito mexicano y la delincuencia femenina durante el siglo XVIII, refiere que el hurto y robo solo representarían un 3,27\%. Citamos aquí este ejemplo como muestra de los distintos comportamientos según el ámbito de estudio. El propio autor refleja que en el territorio estudiado se detecta un "modelo del vicio" al ser lo más llamativo el que un $48,80 \%$ de los delitos registrados en las fuentes que utiliza se corresponden con delitos de embriaguez.

19 Ángel Alloza, La vara quebrada de la justicia. Un estudio histórico sobre la delincuencia madrileña entre los siglos XVI y XVIII, Madrid, Los Libros de la Catarata, 2000, p. 143. Como señala el autor, Castilla no fue ajena a ese fenómeno en el que los delitos en "daño común" habían sido ya protagonistas en momentos previos a la Edad Moderna.

20 Ricardo Córdoba de la Llave, "Marginalización social y criminalización de las conductas”, El mundo social de Isabel la Católica: la sociedad castellana a finales del siglo XV, coordinador Miguel Ángel Ladero Quesada, Madrid, Dykinson, 2004, p. 297.

${ }^{21}$ Dubert especificó entre los factores que más incidían en esas estancias prolongadas de las criadas en casas de sus amos "la combinación de condición femenina y carencia de 
ocasiones, cometiesen numerosos hurtos 22 . Ante la ejecución de estos delitos, en algunos casos se va a proceder contra las mozas. Se originaban así una serie de pleitos que, tras pasar por las justicias inferiores, acababan llegando al tribunal de la Real Chancillería de Valladolid y, en concreto, a su Sala de lo Criminal. Nos detendremos ahora, por su interés, en conocer a estas mozas que son acusadas de hurto a finales del Antiguo Régimen ante dicha justicia ${ }^{23}$.

Unas mozas de servicio que en ocasiones ejercen como tal a pesar de su corta edad ${ }^{24}$. Quince años, poco más o menos, declaró tener la criada Prudencia Astorga, natural de Valladolid, quien fue acusada por parte de su amo, Josef Calvo, de salir a deshoras sin permiso de este, todo ello unido a fuertes sospechas de que le robaba varias de sus pertenencias. Entre los objetos sustraídos el propio amo expresó que "por malicias le estraia algunos efectos como sábanas, ropa blanca y pan cocido"25. Los diferentes testigos fueron aportando información detallada sobre los distintos hurtos que la acusada había ido llevando a cabo. Así, es otra criada de la misma

medios, las magras ganancias que les reportaba el oficio, las escasas expectativas de futuro que este ofrecía y la baja posición que como criadas ocupaban en la escala social", Isidro Dubert, "Criados, estructura económica y social y mercado de trabajo en la Galicia rural a finales del Antiguo Régimen”, Historia Agraria, n 35, Murcia, 2005, p. 11.

${ }^{22}$ Sobre el significado y evolución del concepto hurto y robo, así como su utilización, vid. José Sánchez-Arcilla Bernal, "Robo y hurto en la Ciudad de México a fines del siglo XVIII", Cuadernos de Historia del Derecho, ${ }^{\circ}$ 8, Madrid, 2001, pp. 49-74.

23 Nos centraremos en aquellos casos en los que las criadas fueron acusadas de ejecutar el delito contra la propiedad, si bien no debemos olvidar, que se dieron otras situaciones en las que las criadas sufrieron el hurto/ robo o las consecuencias del mismo. Como mero ejemplo de lo segundo, podría servirnos el robo perpetrado en la noche del 13 de noviembre de 1777 en la casa de Jerónimo Díez y en el que salieron lastimados el susodicho, su mujer, una viuda, y la criada de la casa. En el testimonio que certificó Sebastián Franco de Quirós, escribano público y del número de la villa de Ledesma, se indicaba que Jerónimo Díez "se hallaba a la puertta de su casa grabamente herido y atadas sus manos con un cordón y asimismo su criada con una liga y que le habían enttrado diferentes hombres en su casa", Valladolid, Archivo de la Real Chancillería de Valladolid (A.R.Ch.V.), Sala de lo Criminal, 340, 3, f.18r.

${ }^{24}$ Esta fue una característica común de las componentes del servicio doméstico, tanto en el ámbito castellano como fuera de él. Por citar un ejemplo podemos señalar cómo las mozas de servicio de la ciudad de Salamanca, durante la primera mitad del siglo XVII, se caracterizaron, a este respecto, porque la mayor concentración de mujeres que pasaron a ejercer de criadas lo hicieron en la franja existente entre los 15 y los 25 años, siendo la edad modal de 17. Solamente un $7 \%$ habría superado los 25 años. Francisco Javier Lorenzo Pinar, "Los criados salmantinos durante el siglo XVII (1601-1650): las condiciones laborales (I)", Obradoiro de Historia Moderna, n 18, Santiago de Compostela, 2009, p. 242.

25 Valladolid, A.R.Ch.V., Causas secretas, 33, 1, f.1v. 
casa, Ana Mogrobejo, natural del lugar de Fuentes de Carvajal (León), y de 20 años, quien dijo que había oído a su amo que Prudencia Astorga había tomado de él una camisa y de su hija unas enaguas, y que conocía que la acusada había dado seis panes a un muchacho forastero, dándole a la declarante dos reales para que no dijese nada, quien, por otra parte se los dio a la ama sin especificar de donde provenían. Entre los testimonios ilustrativos aparece el de otra criada, María de la Cruz Orcajo, natural del lugar de Valñas, tierra de Sepúlveda, de 14 años, quien vio un mes antes de su declaración que Prudencia Astorga había cogido seis panes de su amo y se dirigía con ellos hacia la cuadra con el fin de dárselos a un zapatero para que hiciese a su hermano un par de zapatos. La testigo incluso fue más allá, acusándola también del robo de dinero, pues declaró que tres meses antes "estando en el portal de su casa el citado su amo Josef Caluo contando dinero de plata en una criba se quedó medio adormecido y entonces vio la testigo que la enumciada Prudencia metió por dos veces la mano en dicha criba" 26 confesándola que había cogido dos reales de plata. Frente a todas esas acusaciones, Prudencia declaró que todas, junto con otras de otros testigos, eran falsas, y que si lo decían sus compañeras y hermana era solo con el fin de dejarla mal a ella, pues no se consideraba cómplice de ningún hurto. Por lo tanto nos encontramos cómo, frente a una serie de acusaciones de su círculo más cercano, familiar, pero sobre todo de otras compañeras que ejercían en la misma casa de domésticas, la acusada va a negar todo lo referido. Pero incluso llega más allá, explicando de dónde procedía cada elemento supuestamente sustraído ${ }^{27}$. La sentencia del gobernador y alcaldes del crimen de la Real Chancillería de Valladolid llegó en 1804, cuando a Prudencia se la condenó a ocho días de prisión, dándole además un plazo de quince días para que

26 Ibidem, f.3v.

27 Así señaló que los 298 reales y medio que obraban en poder del que fue alcalde de barrio "no eran de la declarante y sí de su nobio Juan Merino que los iba poniendo en la arca de la declarante para quando se casasen de lo que le producía su trabajo y leña que diariamente traía del pinar; que las dos sábanas que existían en poder del receptor fueron encontradas en el arca de la declarante eran de ella misma las que compró hauia mucho tiempo sin que se acordase a quien y las tenía para quando se casase con el citado Merino", Ibidem, f.4r. 
"buscase amo donde seruir con la fidelidad deuida u otro modo de vivir onesto pues de lo contrario se la haría desocupar esta" ${ }^{28}$; a todo ello se sumaba la condena a todas las costas, así como el apercibimiento de que si volviese a reincidir se la condenaría a ocho años de reclusión en la Casa Galera.

Un recurso frecuentemente utilizado por parte de estas mozas acusadas de hurto fue el de argumentar que aquellos objetos y bienes que se pensaban sustraídos no eran tales. Tomemos ahora como ejemplo a la moza María Cruz Álvarez, natural de Valladolid, de 18 años y huérfana, quien fue acusada, llevando tan solo ocho meses de servicio, del robo de varias alhajas de la casa de don Manuel Acosta, relator de la Real Chancillería de Valladolid. Esta, a través de Matías Serrano Linacero, procurador de la Chancillería, y su curador ad litem, confesó que se halló en su poder un pañuelo de cuatro esquinas bordado y una sortija de diamantes del citado relator. Sin embargo, a continuación declaró "que la sortija la halló al pie del catre de su amo al tiempo de hacerle la cama el día antes de salir de la casa de sus amos y que haviendola custodiado en el bolsillo con ánimo de entregársela a su ama luego que volviere de paseo se la olvidó..."29, sucediendo algo similar con el pañuelo pues le "embolvio con su ropa sin advertirlo al tiempo de recogerla para marchar..."30 dándose cuenta de que se había llevado ambos objetos al llegar a su casa. Y es que desde la defensa de la criada se va a argumentar todo lo posible con el fin de que no fuese condenada y justificar su actitud. Siguiendo en este mismo pleito criminal, encontramos el siguiente relato que explica el porqué no había devuelto dichos bienes, pudiéndose sintetizar en que la distinta posición del amo y la criada explicaba lo sucedido:

\footnotetext{
"Porque quien duda que los altercados que entre amos y criados ocurren en estos lances, al mismo tiempo que les enconan los ánimos abaten el espíritu de los últimos que por dependientes e inferiores
}

\footnotetext{
28 Ibidem, f.4v.

29 Valladolid, A.R.Ch.V, Sala de lo Criminal, 386, 10, pieza 1, f.2r.

30 Idem.
} 
tienen que ceder aun a las sin rrazones y que por lo mismo no quedan en libertad de hacerles ni las representaciones más justas oprimidos de superioridad que les impone silencio, no es mucho pues que por una parte el respeto y por otra el justo temor de renovar las contiendas la hiciesen perezosa en la restitución..."31.

El 11 de agosto de 1808, el gobernador y alcaldes del Crimen de la Real Chancillería de Valladolid condenaron a dos años de reclusión de Galera a la susodicha, siendo el uno preciso y dejando el otro a la voluntad de la Sala; además, debería restituir a su amo la sortija y el pañuelo bordado y se le condenaba también en todas las costas de la causa. Inserto en la sentencia, como era habitual, figura el apercibimiento por el cual se la instaba a que, en lo sucesivo, arreglase su conducta pues, en caso contrario, si volviese a reincidir, sería castigada con mayor rigor.

Dentro de la reconducción de estas mozas de servicio que se habían "desviado" del modelo de mujer propuesto desde la Iglesia y el Derecho, como estamos comprobando, la reclusión en la Casa Galera, que "funcionaba con un discurso moralizador y correccional además del estrictamente represivo"32, fue un recurso frecuente 33 . Algunas criadas fueron condenadas a pasar un determinado tiempo en ella, mientras que otras fueron apercibidas de que, en caso de no corregir sus comportamientos, acabarían allí. En este pleito resultan interesantes los argumentos expuestos por Matías Serrano en nombre de María Cruz Álvarez al conocer la sentencia y que van a perseguir evitar la Galera. En primer lugar, consideró perjudicial su reclusión en la Galera pues

31 Idem.

32 José Miguel Palop Ramos, "Delitos y penas en la España...", p. 96.

33 No es algo que deba sorprendernos, pues en aquellos momentos "la mujer era condenada a privación de libertad, esperando su reinserción moral, mientras que el hombre era sentenciado a penas de utilidad social para las monarquías modernas", Margarita Torremocha Hernández y Carlos Lozano Ruiz, "Galera y taller. El utilitarismo ilustrado según la "Instrucción" de A. González Yebra”, La prisión y las instituciones punitivas en la investigación histórica, coordinadores Pedro Oliver Olmo y Jesús Carlos Urdá Lozano, Cuenca, Ediciones de la Universidad de Castilla La Mancha, Colección Estudios, $\mathrm{n}^{\circ} 141$, p.195. 
"tampoco el delito en sí arguye una perversidad de corazón que haya menester una corrección dilatada, ni una severa penitencia; acaso la dilatada prisión de un año o más en la Galera pervertiría con el contagio de una mala sociedad sin corazón sensible todabía a los remordimientos de conciencia y aguisado por los sentimientos del honor" 34 .

Pero también veía en esa reclusión "tan infamatoria y humillante como la de Galera que siendo en esta corte habría de sufrirla a vista de sus parientes y allegados" 35 . Hasta tal punto va a evitarlo que va a pedir la conmutación de la pena por seis años de destierro, con todo lo que ello podía originar en aquella sociedad moderna.

En otras ocasiones, en estas causas se llega a apreciar la existencia de algunos agravantes al hurto propiamente cometido por la moza de servicio. Para el período que aquí estudiamos el más significativo es, sin duda, el mantener relaciones con soldados. Entre los distintos ejemplos que podemos citar al respecto, nos centraremos en el caso de Josefa Gómez, criada que se define a sí mismo como "criada jornalera” pero que como otras muchas se caracterizaron en lo laboral por su versatilidad. En el auto de oficio que lleva por fecha 15 de agosto de 1802, dicha criada, natural de Valladolid, resultó acusada del robo de 800 reales de un talego que su amo, Antonio Herrero, guardaba en un arca. Y, más allá del hurto propiamente dicho, del que resultó delatada por un hijo pequeño del amo, va a ser constantemente acusada de que "no es de la mejor conducta por haberla bisto andar con soldados que pernotaba algunas vezes fuera de la casa de sus padres sin su lizencia y consentimiento" 36 . Unas acusaciones que eran totalmente ajenas al tema por el que se la juzgaba, de carácter moralizante y, en definitiva, metajudicial, pero que ponen de manifiesto que la mujer siempre va a ser juzgada ante determinados comportamientos condenados por la Iglesia y por esta sociedad sacralizada (a pesar de las fechas), aunque no respondan a tipo delictivo

\footnotetext{
${ }^{34}$ Valladolid, A.R.Ch.V., Sala de lo Criminal, 386, 10, pieza 1, f. 9r.

35 Ibidem, f. 9v.

36 Valladolid, A.R.Ch.V, Sala de lo Criminal, 681, 7, f. 1r.
} 
alguno. En este caso la criada se desdijo en su declaración indagatoria de dichas acusaciones, afirmando que no se acompañaba de soldados ni tenía amistad con ellos, así como que nunca se había quedado fuera de la casa de sus padres sin su licencia. Este tipo de comportamientos agravaba, sin duda, el delito de hurto del que se la acusaba, como también lo agravó el que su propia madrastra, María García, mujer del padre de la susodicha, Ramón Gómez, en terceras nupcias, se llegara a quejar que desde la cárcel Josefa la provocara "con canttares propios de su mala conductta" 37 , hasta el punto de que tanto uno como otro llegaron a solicitar su entrada en la Galera. Por lo tanto, frente al delito inicial, el hurto de los 800 reales, encontramos cómo toda una serie de acusaciones, sobre todo referentes a su trato con los soldados, van a confluir alrededor de la susodicha. El 13 de septiembre de 1802 se apercibió por el gobernador y alcaldes del crimen de la Chancillería a Josefa Gómez "que en adelante ebite las sospechas que contra ella resultan y viva con la honestidad y recato que corresponde pues de lo contrario se la destinará por quatro años a la Real Cárcel de esta corte y se la condena en todas las costas..."38.

Una vez que las mozas de servicio perpetraban el delito contra la propiedad optaban, o bien por negar lo hurtado y permanecer en la casa del amo, como hemos analizado en algunos de los ejemplos anteriores, o bien por recurrir a la fuga. Esta segunda vía fue a la que recurrió Fermina Antolínez, de 17 años de edad, natural de Carrión de los Condes (Palencia) y criada del don Félix José de Urrengoechea, tras hurtar varios bienes a su amo. La susodicha fue hallada en su huida desde la ciudad de Valladolid, donde servía, hacia su localidad natal, en la villa de Wamba. Así, Manuel Urrea, vecino de Valladolid al que se le había encomendado que indagase el paradero de Fermina Álvarez, se presentó, tras varias sospechas, en Wamba, donde, en casa de la conocida como "la carretera", encontró a la susodicha que, tras proceder a su registro, fue dirigida de nuevo hasta la casa de su amo. Ella misma confirmó en su declaración que la causa de su prisión era "por haberse fugado de la casa de su amo llebándose

\footnotetext{
37 Ibidem, f.16v.

38 Ibidem, f.19v.
} 
varias ropas y otras cosas"39. Unas ropas que, por lo tanto, confirmó haber hurtado y habérselas llevado consigo en su fuga, a diferencia de otra serie de bienes de cuyo hurto también fue acusada y ella negó ${ }^{40}$. El 1 de agosto de 1811, el gobernador y alcaldes del Crimen de la Real Chancillería, vistos los autos, y teniendo en cuenta la prisión ya sufrida por Fermina, la condenaban a un mes en la Casa Galera de esta Corte y al pago de las costas de la causa; asimismo se la apercibía a que no reincidiese en los excesos cometidos, pues sería castigada con mayor rigor.

Negación de lo hurtado, fuga, pero también, en ocasiones, las mozas de servicio, ante sospechas de posibles delitos cometidos contra la propiedad de sus amos, podían llegar a ser expulsadas de la casa. Esto es lo que sucedió en 1788 con María Riesca, criada soltera de 22 años, natural de Astorga. Esta había ido a Valladolid y, tras pasar dos años sirviendo en un mesón en la Rinconada de Santiago, y otro tiempo haberlo pasado enferma en el Hospital de Esgueva, había ido a servir a la casa de Francisco Urueña, escribano del número de dicha ciudad. El servicio en dicha casa, sin embargo, fue efímero, pues duró "como cinco días" ya que María Manuela Calvo, mujer del amo, atisbó que "la había extraído barias alajas y entre ellas vn tenedor de plata, vna tabla de manteles nueba, y vna chupa de seda" ${ }^{41}$. Y es que, como la propia María Manuela Calvo declaró "a los dos o tres días de recibida la hubiere adbertido la testigo deseosa de salir de casa con bastante altanería poniéndose al valcón y trabado combersación con vn soldado de la vandera que está a el frente de la casa de la testigo" ${ }^{2}$ y con el que la susodicha según parece mantenía una estrecha relación. Encontramos pues, de nuevo, ese agravante que sin duda supuso el trato de las mozas de servicio con los soldados.

39 Valladolid, A.R.Ch.V., Sala de lo Criminal, 827, 9, f. 4r.

40 A mayores de dicha ropa se la acusó también de haber robado una manta, dos fundas, un par de medias blancas con cuadrado bordado, dos pañuelos de batista, otras ropas, alhajas, cubiertos de plata, etc. sobre los que argumentó no haberlos hurtado y así, por ejemplo, en el caso de las medias de seda indicó que se encontraban en el desván de la casa de su amo envueltas en una estera, en el caso de los cubiertos de plata que les encontró entre el carbón en la propia casa en que servía, etc.

41 Valladolid, A.R.Ch.V., Sala de lo Criminal, 1747, 2, f.1r.

42 Ibidem, f.2r. 
La expulsión de la casa de María Riesca se tradujo en una búsqueda de la misma, con el fin de que restituyese los bienes robados y pagase por lo sustraído. Según declaró la propia acusada, muy pocos días después de su expulsión de la casa de Francisco Urueña la habían recogido en un cuarto de la calle Rinconada, sin que llegara a recordar el nombre de sus dueños pues solo estuvo una noche porque al día siguiente iba a regresar a su tierra con un maragato. Tan solo cuatro días después de su declaración en la cárcel, en relaciones a 26 de enero de 1788, se apercibía a María Riesca a que en adelante se abstuviese de cometer los excesos que resultaban de los autos, bajo pena de ser reducida a la cárcel Galera de esta corte, "y dentro de terzero día salga desta ziudad y se confine en el pueblo de su naturaleza pena de que se procederá contra ella por todo rigor de derecho" ${ }^{43}$, condenándosela en las costas. Se confirmaba el destino de la criada en cuestión, el regreso a su localidad de origen, hecho que, por otro lado, se encontraba ya, según sus declaraciones, entre sus planes más próximos. Tan solo cuatro meses después de que esta moza soltera hubiese abandonado Astorga, después de haber servido dos meses en un mesón, haber pasado tiempo enferma en el Hospital, y haber servido menos de una semana en una casa en la que se le acusó de hurto, debía regresar, ya bien fuese por voluntad propia o por deseo de la justicia ${ }^{44}$.

Entre los rasgos comunes a las mozas de servicio que pasaron por este tribunal que acabamos de analizar se encuentra el que todas fueron solteras. Eso no quita, sin embargo, para que se puedan detectar puntualmente pleitos cuya protagonista fuera una criada que ya había llegado a contraer matrimonio. Es el caso de Teresa Blanco, natural de Zamora, de 30 años de edad, y que había contraído, según indica, matrimonio con Manuel Adrián, natural de Cádiz, soldado del regimiento de Mallorca. La llegada de Teresa Blanco a Valladolid respondía a su deseo de acompañar a su marido, ya prisionero, hasta ese enclave. Sin embargo, la

43 Ibidem, f.11r.

${ }^{44}$ Si bien el pleito no permite afirmarlo con total seguridad, lo que sí es cierto es que no pocas mujeres, movidas por una información incompleta y sesgada, optaban por llevar a cabo una emigración que, en ocasiones, acababa con las expectativas frustradas. Vid. Ofelia Rey Castelao, “Mujeres, trabajo y migraciones urbanas...”, p. 46. 
salida de este de dicha ciudad poco tiempo después, y la muerte de uno de sus hijos, la llevaron a la búsqueda de recursos para su subsistencia y la del resto de sus descendientes por medio del servicio doméstico en la casa del cirujano don Jacinto Maizonada, pero también la llevó a delinquir en la misma. Estando allí sirviendo, y días antes de que cumpliese un mes de servicio en dicha casa, Teresa, conocida con el apelativo de "la prisionera", perpetró así un hurto con el fin de poder "retirarse a Zamora con el producto que de ello sacase pues le inclinava el volver a ber a tres hijos que tiene en aquella ciudad y en la casa de ospicio" ${ }^{45}$. La lista de objetos que la susodicha habría hurtado, según lo declarado por su amo, se componía de "una manta, tres sávanas, un almirez, seis basos de cristal, una fuente de piedra, unos basos de acuartillo, barios platillos finos, dos salvillas de peltre grandes y baria porción de carbón grueso y piña" 46 dando la propia doméstica los datos sobre a quién había vendido cada cosa ${ }^{47}$. Vinculada con ese hurto se encontraba la huida de la moza de servicio, pues se había "marchado sin haverla despedido ni dicho cosa alguna pues dejó a el declarante y su familia en la mesa esttando comiendo" 48 . Poco tiempo después fue encontrada en una casa del barrio de San Juan de la misma ciudad y, además de negar cualquier posible hurto, afirmó que la salida de la casa de su amo se debía a la imposibilidad de poder dormir en ella por el elevado número de enfermos que había allí. Al fiscal del rey no le tembló la mano a la hora de determinar que Teresa había cometido un delito de los de mayor gravedad y trascendencia, perjudicial para la tranquilidad de las familias, como era el del robo doméstico. Finalmente,

45 Valladolid, A.R.Ch.V., Sala de lo Criminal, 831, 2, pieza $3^{\text {a }}$, f.10r.

46 Valladolid, A.R.Ch.V., Sala de lo Criminal, 831, 2, pieza $2^{\mathrm{a}}$, f.1r.

47 Así, la manta la vendió junto con una sábana a una tendera de aceite y vinagre que vivía en la calle de Orates por 24 reales, otra sábana la vendió a un platero llamado Juan por una peseta, el almirez se lo vendió a un latonero que vivía en la Platería por 11 reales, respecto al carbón dio un poco a la llamadora del Rosario y otra parte lo utilizó ella para su consumo... En todo caso, también resulta interesante el que, como ya hemos señalado anteriormente, la criada argumente que algunos de los objetos de los que se le acusaba haber hurtado no habían sido sustraídos y permanecían bajo poder de su amo, como sería el caso de los platillos finos y las dos salvillas, que no las habría cogido ella pues, según su versión, las salvillas se encontraban debajo de la cama del hijo de su amo.

48 Valladolid, A.R.Ch.V., Sala de lo Criminal, 831, 2, pieza $3^{\text {a }}$, f.2r. 
el 26 de enero de 1813, se condenaba, por el gobernador y alcaldes del crimen de la Real Chancillería, a Teresa Blanco a seis meses de reclusión de Galera, apercibiéndola de que, en el caso de reincidir en semejantes excesos, se la trataría con mayor rigor, así como también al pago de las costas mancomunadamente con otra serie de personas que se habían visto inmersas en la causa. Este pleito nos da también información de otro de los recursos a los que estas mozas de servicio se aferraron en más de una ocasión para justificar el hurto: la tentación inferida por el demonio. $\mathrm{Y}$ es que, aunque Teresa Blanco afirmó saber "que ninguno tiene ación por estar prohivido por derecho el tomar lo ajeno contra la boluntaz de su dueño" ${ }^{49}$, cometió el delito "por averla tentado el demonio"50 .

Solteras, casadas, y también viudas, van a engrosar las filas del servicio doméstico a finales de la Edad Moderna. Sin duda el peso de las criadas solteras fue fundamental, sobre todo si tenemos en cuenta, como ya vimos, que el fin más importante de muchas de las mujeres que se colocaban como domésticas era la de obtener una dote de cara al matrimonio ${ }^{51}$. Sin embargo, y aun reconociendo ese fuerte peso, lo cierto es que "no era una actividad exclusiva de las solteras, ya que la viudez llevaba a muchas mujeres a emplearse como criadas" 52 . Viudas como Sabina Caballero, de 37 años de edad, natural de Cigales (Valladolid) y que, si bien había recurrido a la emigración desde el ámbito rural al urbano cuando todavía vivía su marido, fabricante de paños, finalmente optó, siguiendo lo reconvenido por el rector del Colegio de los Niños de la Doctrina, por ir a la localidad de Rueda (Valladolid), donde se puso a servir en la casa de don Francisco Arévalo. Todo parece indicar, según

49 Valladolid, A.R.Ch.V., Sala de lo Criminal, 831, 2, pieza $2^{\text {a }}$, f.2v.

50 Ibidem, f.1v.

51 Serrana Rial indicó la imposibilidad de cuantificar su peso respecto al total de las mozas de servicio para un momento previo al siglo XIX. Sin embargo, las cifras que aporta son muy esclarecedoras, basándose en el Padrón de 1844 y el Censo de 1857, pues de la primera fuente se extrae que el $96,2 \%$ de las domésticas eran solteras y de la segunda que dicho porcentaje alcanzaría el 94,6 \%. Serrana M. Rial García, Las mujeres en la economía urbana..., p. 113.

52 Ofelia Rey Castelao, "Mujeres en la economía campesina", Historia de las mujeres en España y América Latina. El mundo moderno, directora Isabel Morant, coordinadores M. Ortega, A. Lavrin y P. Pérez Cantó, Madrid, Cátedra, 2005, p. 278. 
se desprende del pleito, que, a diferencia de otras muchas mujeres que sirvieron como criadas, en su mayoría solteras y que carecían de recursos económicos, no fue esta la realidad, al menos inicial, de Sabina Caballero. Así, si bien durante su estancia como presa, por el hurto que su amo le va a atribuir, sabemos que fue contemplada como pobre de solemnidad $^{53}$, era hija legítima de Manuel Caballero y Rosa Marcos, miembros de las familias más conocidas y honradas de su pueblo, a lo que podemos sumar el que, según la declaración de la testigo Manuela Palomo, de 22 de mayo de 1807, "antes de marcharse la Sabina a Rueda la consta a la declarante tenía mui buenos reales y aun quería con ellos poner su trato de comestibles" 54 . Los testimonios dados a favor de la intachable conducta que Sabina había manifestado durante toda su vida ${ }^{55}$ no fueron óbice para que el auto definitivo del alcalde mayor de Rueda, de 23 de junio de 1808 , contemplase la restitución de los pañuelos de yerbas pintados de colores y de blanco, los calzoncillos, media camisa, cinco calcetas, cuatro pastillas de chocolate y el azúcar a su amo, así como una pena de veinte ducados aplicados a penas de Cámara, y el pago de todas las costas de esta causa y gastos de su manutención. Del mismo modo se la apercibía de que sería

53 El que las mozas de servicio fuesen contempladas como pobres de solemnidad durante su estancia en la cárcel es algo que hemos podido constatar en varios de los pleitos criminales analizados. En este caso, posiblemente la situación de la acusada se viese agravada por su situación de viudez, pues por ella había perdido la protección de "un sistema jurídico matrimonial que hace pasar a las mujeres de la tutela/curatela de sus padres a la de sus esposos" (José Luis Arroyo Vozmediano, "Iglesia, mujeres y violencia. Calahorra 1643-1713", Kalakorikos, $\mathrm{n}^{\circ}$ 13, Calahorra, 2008, p. 145). El paso de las mujeres por la cárcel en espera del momento en que se dictase la sentencia las hacía perder la obtención de toda una serie de ingresos fundamentales para su subsistencia. Esto explica que, por ejemplo, en un pleito ya algo tardío, de 1834, en el que Bonifacia Álvarez, viuda, y su hija, Paulina Nuevo, habían resultado acusadas del hurto de cuatro medias onzas de oro en la casa en la que servía la segunda, encontremos que Felipe Benito Alonso, en nombre de ambas, que habían pedido se las defendiese como pobres de solemnidad, solicitase su puesta en libertad "aunque sea dándolas ciudad y arrabales por cárcel, para que puedan con su trabajo adquirir lo necesario para su manutención”, Valladolid, A.R.Ch.V., Sala de lo Criminal, 298, 8, f. 8r. Vid. Pedro Ortego Gil, "La ciudad por cárcel”, La prisión y las instituciones punitivas en la investigación bistórica, coordinadores Pedro Oliver Olmo y Jesús Carlos Urdá Lozano, Cuenca, Ediciones de la Universidad de Castilla La Mancha, Colección Estudios, n 141, pp. 49-63.

54 Valladolid, A.R.Ch.V., Sala de lo Criminal, 779, 5, f.24r.

55 Así, Laureano Moyano, defensor de Sabina Caballero, vino a señalar cómo desde la cuna dicha mujer había acreditado su honrada conducta, hasta el punto de que "quando niña, quando adulta, quando casada, quando viuda, quando sirbienta y finalmente en todos los estados progresibos de su vida no se advierte culpa que imputarla" Ibidem, f.40v. 
tratada con mayor severidad en caso de que en aquellas casas que sirviese no lo hiciese con mayor fidelidad y pureza. Sin embargo cuando la sentencia llegó a la Real Chancillería de Valladolid fue revocada, condenándosela, finalmente, a cuatro meses de prisión en la cárcel de la villa, a sumar a los que ya llevaba, al pago de todas las costas de la causa, y a la restitución de los bienes; también resultó apercibida. Un ejemplo donde vemos cómo no siempre debía coincidir el dictamen definitivo del gobernador y alcaldes del Crimen de la Real Chancillería con el de las justicias inferiores.

Los casos hasta aquí analizados han permitido contemplar los delitos contra la propiedad, y en particular los hurtos, ejecutados por algunas mozas de servicio, en solitario, a sus amos. Aunque todo parece indicar que la participación de más de una moza de servicio en los hurtos era bastante menos frecuente, podemos citar al menos un caso. Es el del hurto cometido por las criadas Francisca Tamames, natural del lugar de Valdelosa (Salamanca) y Eulogia Rodríguez, natural del lugar de Pelabravo (Salamanca), en 1822, en la casa de su amo, don José Bohada. El hurto, de una onza de oro y diez reales de un baúl del amo, llevó a que el juez de Salamanca, por auto definitivo de 19 de octubre de 1822, condenase a las dos criadas a la reclusión por un año en una casa de corrección, siendo los padres los que, en caso de no existir dicha casa, deberían velar y vigilar por sus conductas, procurando "se dediquen a un trabajo onesto y no causen escándalo y no las deje servir en casa alguna condenándolas en las costas del proceso" 56 . Desde Chancillería, el 3 de junio de 1823 se revocaba el anterior auto, contemplándose que la pena de cárcel que ya habían sufrido ambas criadas resultaba bastante "para purgar lo que contra ellas aparece del proceso" 57 , así como el pago mancomunado de las costas y, además del ya habitual apercibimiento, se contempla que el corregidor de Salamanca remitiese a ambas a sus respectivos padres "a quienes se encarga observen la conduzta de sus hijas y procuren ebitar que incurran en adelante en estravíos como el que motivó la formación de la presente" 58 .

\footnotetext{
56 Valladolid, A.R.Ch.V., Sala de lo Criminal, 901, 2, f.3r.

57 Idem.

58 Idem.
} 
Dentro de la casuística de este tipo de delitos en los que las mozas de servicio tuvieron un cierto protagonismo, conviene reflejar un pleito que introduce dos elementos nuevos a lo visto hasta ahora: por una parte, el hecho de que el delito no se comete contra los bienes del amo y, por otra, el que la moza de servicio aparece cooperando con otros miembros de la unidad familiar. El hurto de los bienes en cuestión ${ }^{59}$ se produjo la noche del 12 al 13 de agosto de 1810 en la habitación de don Hilario Gómez y, como sospechosos, figuraron los inquilinos de la parte baja de dicha casa: don Francisco Pérez de Covarrubias, cabo principal de la Comandancia del resguardo de rentas reales de la ciudad de Segovia; María Chico, su mujer; Bonifacio Chico, hermano de esta; y Eufemia García, criada del citado matrimonio. La criada, natural de Quintanamambirgo, partido de Aranda de Duero (Burgos), y de 17 años de edad, si bien mediante su declaración dio a entender que ella simplemente sospechó del delito por los ruidos, así como por la aparición en la casa de objetos que no eran propios de sus amos, va a ser acusada claramente por parte del hermano de su ama. Así, Bonifacio Chico puntualizó cómo, para el acceso a la habitación de don Hilario, había sido fundamental el papel jugado por la criada quien, una vez que pudieron entrar a la habitación,

59 Las distintas declaraciones no coinciden exactamente respecto a los bienes hurtados. Si tomamos como referencia la declaración de Bonifacio Chico, encontramos como se hurtaron dos o tres docenas de chorizo, ropas, una sábana, una manta, un reloj que estaba colgado en la cabecera de la cama, veinte onzas de chocolate, azúcar, una olla de aceite, garbanzos, pimiento, diferentes jícaras, platos, vasos de cristal de varias clases, papel de abujas, así como otra serie de objetos, como un alfiletero que se apropió Eufemia. Una declaración, que como era habitual, difiere de lo dicho por otros acusados, pero sobre todo también con la relación de efectos que el propio don Hilario aportó. El detallismo de la relación de Hilario, así como el hecho de que algunos efectos que aparecen en la relación no aparecen en la declaración del testigo en lo referente a los comestibles: "de azúcar echo de menos como ocho libras, yten seis docenas de chorizos, yten un pernil de tocino de a veinte y dos a veinte y seis libras su peso, yten un celemín de sal, yten dos celemines de garbanzos [...] yten tres onzas de azafrán..." Valladolid, A.R.Ch.V., Sala de lo Criminal, 401,5 , pieza $2^{a}$, f. $46 \mathrm{v}$. Se trata en todo caso de efectos de rápido consumo y que "es parte de la práctica de la rapiña dentro de la casa que los servidores ejecutan contra sus amos pero, tal como vemos, también entre ellos para evitar que al hallarlas en su posición sirviesen de testimonio de su delito", una práctica que se puede vincular, respecto a su objetivo, a la venta inmediata de la ropa hurtada por las criadas, como vimos en el caso de Teresa Blanco. Vid. Ana Inés Rodríguez Gilés, "La socialización marginal de los criados. Análisis de una relación a través de algunos ejemplos presentes en el Guzmán de Alfarache", Cuadernos de Historia Moderna, $\mathrm{n}^{\circ}$ 18, Madrid, 2013, p. 130. 
"la Eufemia vajava a la puerrta principal de la calle para espiar por dentro si se percivía acercarse jente" ${ }^{60}$. Posiblemente esa contrariedad de testimonios, así como otra serie de elementos, llevó a que el promotor fiscal solicitase para la criada, que es la que aquí nos interesa, la pena de cárcel por algunos meses, hasta que el tribunal considerase suficientemente purgados sus excesos. A pesar de ello, finalmente los alcaldes del crimen de la Real Chancillería vinieron a confirmar, el 7 de septiembre de 1811, el auto definitivo del regidor del Ayuntamiento de Segovia, de fecha 16 de julio de dicho año. Mediante este se declaraba cómplice auxiliante a Eufemia y, si bien los cuatro deberían mancomunadamente proceder a la restitución de los bienes, así como al abono y satisfacción de daño y perjuicios, y costas de la causa, solamente Bonifacio Chico resultaba condenado a mayores a cuatro años de trabajos públicos para la patria y, en su defecto, para la ciudad de Segovia.

Una relación totalmente distinta es la que mantuvo la criada, Isabel Paredes, con su amo y su entorno familiar más cercano. Esta, natural de Olea (jurisdicción de Herrera de Pisuerga, Palencia) y sirviente en la casa de Simón Herrero en la villa de Baillo (Burgos) fue acusada del hurto de cuatro mil ducados, que supuestamente acaeció el 5 de agosto de 1788, de un cajón en el que su amo, por descuido, había dejado la llave puesta. Ante la inmediata sospecha de su amo de que se había cometido un hurto, y con la colaboración de otros domésticos y del sacerdote don Josef Burgos, la moza declaró que había cogido algún dinero pero que lo restituiría y, al intentar indagar su paradero, esta señaló un agujero del pajar como el lugar donde lo había ocultado. Una vez que el amo comprobó que allí no se encontraba dinero alguno "creyendo mi partte que todo era arttificio con tal que la criada intentaba oculttar su delitto no pudo menos de irrittarse contra ella y proceder a darla unos golpes de mui cortta consideración” ${ }^{61}$. Unos maltratos que fueron en aumento y que se produjeron durante varios de los días posteriores al delito supuestamente cometido por la criada. El pleito criminal en cuestión permite apreciar, mediante distintas declaracio-

\footnotetext{
60 Valladolid, A.R.Ch.V., Sala de lo Criminal, 401, 5, pieza $2^{\mathrm{a}}$, f.43v.

61 Valladolid, A.R.Ch.V., Sala de lo Criminal, 221, 1, pieza $2^{a}$, f.4r.
} 
nes, como las de los cirujanos, el débil estado de salud de Isabel Paredes tras recibir las sucesivas palizas ${ }^{62}$. Estas, impartidas por el círculo más cercano del amo, en el que se encontraban Ignacio Herrero, su hijo, Juan Pérez, su yerno, y sus primos Marcelino Herrero y Manuel Guerra, buscaban no solo el castigo sino hacerla confesar como culpable y hallar el lugar donde había escondido la elevada cantidad de ducados desaparecida. Esto explica, por ejemplo, el que Marcelino Herrero y Manuel Guerra "la reconvinieron aprontase el dinero que faltaba a su amo que si no la havian de dar una buena manta de azotes y después la habían de colgar, abrirla de arriba abajo y hechar en un pozo"63 siendo la respuesta de la criada ante ello "que hiciesen lo que quisiesen que ella no avía sido, ni lo tenía, ni sabía de tal dinero"64. Desde el punto de vista que aquí nos interesa nos encontramos, pues, ante el caso de una moza de servicio en el que, ante la sospecha de que hubiera cometido un hurto, no solamente su amo, sino su círculo más cercano, buscó tomarse la justicia por su cuenta, propinándola toda una serie de maltratos.

\section{3-Epílogo}

A través de este estudio, basado en la práctica judicial, que "siempre supera a la teoría legal y doctrinal" ${ }^{65}$, hemos pretendido analizar algu-

62 Puede servir como ejemplo la declaración de don Francisco García, médico titular del lugar de Villota del Duque, efectuada el 23 de julio de 1798, y donde destaca la fuerte inflamación, así como otros síntomas, de la criada: "Haviéndolo executado la hallo con una fiebre sinttomatica de la graue commoción que recibieron los espíritus a causa de la gran contorsión que padecieron los sólidos por los muchos golpes que llevaron con instrumentos contundentes que manifiestan los grandes quimosis que tiene en lo más de la periferia por lo que considera larga su curación, y aprobó las dos sangrías echas por el zirujano partidario y mandó se la hiciese otra mediante averle relacionado la emferma y dicho zirujano se la hauia detenido la purgación con que se hallava a el tiempo de dichas estorsiones y además la aplicó los medicamentos ynteros que según su arte y facultad están yndicados", Valladolid, A.R.Ch.V., Sala de lo Criminal, 221, 1, pieza $3^{\mathrm{a}}$, ff. $5 \mathrm{r}-\mathrm{v}$.

63 Ibidem, f.3r.

64 Idem.

65 Pedro Ortego Gil, "Sentencias criminales en Castilla: entre jueces y abogados", Clío E Crimen, $\mathrm{n}^{\circ} 10$, Durango, 2013, p. 372. 
nos casos en los que las mozas de servicio se vieron implicadas en la ejecución de hurtos domésticos. Frente a aquellas hacia las que los amos mostraron cierta afectividad, demostrando esta a través, por ejemplo, de las mandas testamentarias, hemos podido documentar, con nombres y apellidos, algunas de esas "criadas-ladronas" de las que también dan testimonio otras fuentes como la literatura. Unas mozas, las aquí estudiadas, que recurren al hurto y que, aunque en algunos casos ellas lo van atribuir a las tentaciones del demonio, como el propio de una sociedad sacralizada como era todavía aquella, responde al deseo de poder completar e incrementar unos recursos, los obtenidos por ellas, tendentes a lo escaso. Una imagen, la de la criada-ladrona, que se completa, en algunos de los discursos que hemos examinado, con otras críticas hacia estas y que, a la larga, no vinieron sino a agravar los delitos cometidos. Acusaciones como una mala actitud en el servicio, la relación afectiva con los soldados o el acometer acciones sin permiso de sus progenitores, son solo algunos de los ejemplos.

Las diferentes justicias van a velar, una vez cometido el delito, por intentar reconducirlas dentro del marco generado por el discurso, sobre todo de la Iglesia y el Derecho. Aunque las sentencias castellanas tendieron a "ser escuetas y no constar en ellas los fundamentos jurídicos aplicados por el juez en su dictamen final" 66 , junto al resarcimiento y el castigo no suele faltar una llamada a la reconvención de la criada en sus comportamientos. Un resarcimiento que se detecta en no pocas de las sentencias estudiadas en las que se ordena la restitución, por parte de la moza, de los bienes hurtados al amo. Ello con el agravante de que, en ocasiones, esta ya había procedido a la venta de algunos de ellos o a su consumo inmediato. Tal singularidad de las sentencias, y el nivel de la muestra aquí analizado, impide poner en relación la severidad de las penas con distintas variables. Lo cierto es que un elemento común a la inmensa mayoría de ellas es el pago, por parte de dichas mozas, de las costas del proceso; algo que, no lo olvidemos, acababa de resentir muchas veces

66 José Luis de las Heras Santos, La justicia penal de los Austrias en la Corona de Castilla, Salamanca, Universidad de Salamanca, 1991, p. 185. 
la ya de por sí frágil economía de estas mujeres. Y es que, como ha quedado puesto de manifiesto, el simple hecho de la reclusión en la cárcel de la villa o ciudad en la que habían cometido el delito, mientras esperaban la sentencia, se traducía en una pérdida de ingresos fundamentales.

Pero no tienen menos interés los tan habituales apercibimientos que acompañan a estas sentencias ${ }^{67}$. Mediante estos, lo acabamos de ver, desde la justicia inferior, o desde la Chancillería, se buscaba de una manera meridianamente clara hacer una llamada a un cambio en los comportamientos de las mozas. Así, la reconducción de estas mujeres por medio de su reclusión en la Casa Galera, como en el caso de Prudencia Astorga, a la que se apercibió con ocho años en ella, o el de Josefa Gómez, con cuatro, o el de Teresa Blanco, que directamente fue condenada a seis meses, fue un recurso recurrente. No faltó tampoco en esos apercibimientos la clausula que indicaba que, en caso de no arreglar su conducta, la justicia sería más rígida contra ellas y actuaría con mayor rigor; o aquella por la se la reconvenía a que, en la nueva casa en que entrase a servir, mantuviese una mayor fidelidad con su amo, fidelidad que, mediante la ejecución de hurtos, estas mozas habrían quebrantado.

67 Pedro Ortego Gil, "Apercibimientos penales en la práctica criminal de la Real Audiencia de Galicia (siglos XVII y XVIII)", Cuadernos de Historia del Derecho, 3, Madrid, 1996, pp. 11-42. 
Série Investigação

Imprensa da Universidade de Coimbra

Coimbra University Press

2015 